\title{
Simple Route for the Synthesis of Copper Hydroxy Salts
}

\author{
Jhon Mauricio Aguirre, ${ }^{a, d}$ Adamo Gutiérrez ${ }^{b, d}$ and Oscar Giraldo ${ }^{*, c, d}$ \\ ${ }^{a}$ Departamento de Ingeniería Química, ${ }^{b}$ Departamento de Ingeniería Eléctrica, \\ Electrónica y Computación, ${ }^{c}$ Departamento de Física y Química and \\ ${ }^{d}$ Laboratorio de Materiales Nanoestructurados y Funcionales, \\ Universidad Nacional de Colombia, Carrera 27 No. 64-60, Manizales, Colombia
}

\begin{abstract}
No presente trabalho é apresentada uma nova e rápida rota de síntese em escala de laboratório de hidroxinitrato de cobre(II), $\mathrm{Cu}_{2}(\mathrm{OH})_{3} \mathrm{NO}_{3}$, mediante reação de hidróxido de magnésio com solução aquosa de nitrato de cobre(II). O material foi caracterizado por difratometria de raios X (estrutura monoclínica), absorção atômica, espectroscopia vibracional (infravermelho com transformada de Fourier e Raman), análise térmica e microscopia eletrônica de varredura com EDX.
\end{abstract}

The current work introduces a new and rapid synthetic route for the in-laboratory preparation of copper hydroxy nitrate, through the reaction of magnesium hydroxide and copper nitrate aqueous solution. The material with the formula $\mathrm{Cu}_{2}(\mathrm{OH})_{3} \mathrm{NO}_{3}$ and monoclinic phase was characterized by $\mathrm{X}$-ray diffraction, atomic absorption, Fourier transform infrared and Raman spectroscopy, scanning electron microscopy with EDX, and thermal analysis.

Keywords: hydroxy salts, anionic clay, copper hydroxynitrate, gerhardtite

\section{Introduction}

Two-dimensional solids have gained increasing interest in recent years given to possible applications in many fields, particularly exploring its capacity to intercalate ionic or neutral species in the interlayer region. There are several classes of materials with layered structures, that are characterized by weak interactions in the interlayer region. ${ }^{1}$ One of them corresponds to negatively charged aluminum silicates, titanates and birnessite-type manganese oxides. A second group corresponds to neutral lamellar materials like graphite, $\mathrm{MoO}_{3}$-type oxides, and some coordination compounds. A third group corresponds to positively charged layered materials like hydrotalcite and some hydroxy salts of transition metal ions. ${ }^{2-4}$

The hydroxy salts (HS), also known as basic metallic salts, ${ }^{1,2}$ encompass a class of layered materials classified within the family of anionic clays, and they resemble layered double hydroxides (LDH) or hydrotalcite-like materials. ${ }^{3,4}$ Their structure are similar to the mineral form of brucite or magnesium hydroxide $\left[\mathrm{Mg}(\mathrm{OH})_{2}\right],{ }^{5}$

*e-mail: ohgiraldoo@unal.edu.co where the $\mathrm{OH}^{-}$anions are hexagonally packed and the magnesium(II) ions occupy octahedral sites, forming extended sheets. ${ }^{6,7}$

The copper(II) hydroxynitrate, $\mathrm{Cu}_{2}(\mathrm{OH})_{3} \mathrm{NO}_{3}$, crystallizes in an orthorhombic phase with cell parameters a $=6.087 \AA$, $\mathrm{b}=13.813 \AA$, and $\mathrm{c}=5.597 \AA$. It is naturally found in the mineral called Gerhardtite, but a stable monoclinic phase is obtained by conventional synthetic routes. ${ }^{8-10}$

The structure of $\mathrm{Cu}_{2}(\mathrm{OH})_{3} \mathrm{NO}_{3}$ can be imagined as being obtained by replacement of $25 \%$ of the $\mathrm{OH}^{-}$anions in the cooper hydroxide sheets by $\mathrm{NO}_{3}^{-}$anions directly coordinated to copper(II) cations through one of its oxygen atoms, as shown in Figure 1. The stacking of such a sheets in the $\mathrm{z}$ direction lead to the formation of a neutral threedimensional structure. ${ }^{4,11}$ However, the nitrate ions can be displaced by others negative charged molecules.

Metallic hydroxy salts with the composition $\mathrm{M}_{2}(\mathrm{OH})_{3} \mathrm{X}$ $(\mathrm{M}=\mathrm{Cu}, \mathrm{Co} ; \mathrm{X}=\text { organic anion })^{5,8}$ have been extensively studied because of their interesting magnetic properties, that are strongly dependent on the structure and molecular ordering of intercalated anions, as well as, the interlayer distance determined by them. Accordingly, the properties of those materials can be easily manipulated, such that can be considered tunable magnetic materials. ${ }^{12-21}$ Thus, it is 


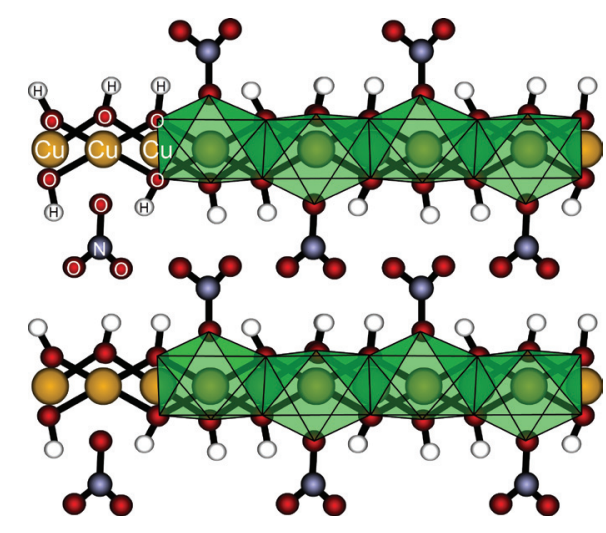

Figure 1. Schematic representation of the structure of copper hydroxynitrate, $\left(\mathrm{Cu}_{2}(\mathrm{OH})_{3} \mathrm{NO}_{3}\right)$.

reported in this work a new simple method for preparation of copper hydroxynitrate, an interesting member of this class of layered materials.

\section{Experimental}

Synthesis

Copper hydroxynitrate, $\mathrm{Cu}_{2}(\mathrm{OH})_{3} \mathrm{NO}_{3}$, was synthesized by the reaction of a dispersion of analytical grade magnesium hydroxide, $\left(\mathrm{Mg}(\mathrm{OH})_{2}\right)$, from BDH Chemicals Ltd. Poole England, with a solution of analytical grade copper nitrate trihydrate, $\left(\mathrm{Cu}\left(\mathrm{NO}_{3}\right)_{2} \cdot 3 \mathrm{H}_{2} \mathrm{O}\right.$, from Merck $\left.{ }^{\circledR}\right)$.

Magnesium hydroxide $(1.01 \mathrm{~g})$ was dispersed in $100 \mathrm{~mL}$ $\left(0.17 \mathrm{~mol} \mathrm{~L}^{-1}\right)$ of distilled and deionized water (DDW) and a copper nitrate solution, prepared by dissolving $10.08 \mathrm{~g}$ of salt in $100 \mathrm{~mL}$ of DDW $\left(0.42 \mathrm{~mol} \mathrm{~L}^{-1}\right)$, such that the $\mathrm{Cu} / \mathrm{Mg}$ molar ratio was larger than 2.

Copper nitrate was kept in excess to promote the complete exchange of magnesium(II) for copper(II) cations, avoiding the possible formation of copper hydroxide $\left(\mathrm{Cu}(\mathrm{OH})_{2}\right)$, copper oxide $(\mathrm{CuO})$, or other non-desirable phases. The reaction was conducted at room temperature and ambient pressure $\left(23.4^{\circ} \mathrm{C}, 585 \mathrm{~mm} \mathrm{Hg}\right)$, for $20 \mathrm{~min}$, with constant magnetic stirring at $1200 \mathrm{rpm}$. The $\mathrm{pH}$ of the initial reaction mixture was about 5.0, but decreased to 4.3 at the end of the reaction, due to the consumption of hydroxide. The resulting precipitate was separated through vacuum filtration with Schleicher \& Schuell filter paper with $2 \mu \mathrm{m}$ pore size.

The solid was washed several times with DDW to remove excess of salts or other soluble impurities. Then, the aqua-marine blue solid was dried at room temperature and relative humidity of $65 \pm 10 \%$. The washing solution was saved for atomic absorption analyses and the aqua-marine blue precipitate was stored for further characterization.

\section{Characterization techniques}

The metal content in the samples were determined by atomic absorption spectrometry (AAS; Perkin-Elmer 3110). The concentration of the solution was adjusted to the equipment's optimal detection readout limits before measurements.

Powder X-ray diffraction analysis were carried out using a Rigaku Miniflex II equipment with Bragg Brentano geometry, equipped with $\mathrm{NaI}$ detector and $\mathrm{Cu} \mathrm{K} \alpha$ radiation source $(\lambda=0.1540562 \mathrm{~nm})$, operating at $30 \mathrm{kV}$ and $15 \mathrm{~mA}$. The X-ray diffraction patterns (XRD) were collected in the $2 \theta$ interval of 3 to $70^{\circ}$ at a scanning speed of $2^{\circ}$ per min, in normal environmental conditions.

The Fourier transform infrared spectra were obtained in a Nicolet 380 spectrophotometer, equipped with a DTGS detector. The samples were prepared by diluting $10 \mathrm{mg}$ of the pulverized solid samples with $\mathrm{KBr}$ and pressing them to form a pellet. Registries were obtained in the 4000 to $400 \mathrm{~cm}^{-1}$ interval with a $4.0 \mathrm{~cm}^{-1}$ resolution.

The Raman spectra were obtained in a HR-800 spectrophotometer (Horiba-JobinYvon), equipped with a $473 \mathrm{~nm}$ excitation laser, in the 400 to $3800 \mathrm{~cm}^{-1}$ range.

The morphology and the composition of the material were examined by SEM/EDX, using a Jeol JSM 5910LV scanning electron microscope equipped with energydispersive X-ray spectrometry detector.

Thermal analyses (TGA and DTG) were conducted in a high-resolution TA Instruments Q-500 $\mathrm{T}_{0}$ thermogravimetric analyzer. The samples were heated in nitrogen atmosphere at a speed of $10^{\circ} \mathrm{min}^{-1}$, from room temperature to $800^{\circ} \mathrm{C}$.

\section{Results and Discussion}

Generally, hydroxy salts are synthesized by one of the following methods: the pyrolysis of a metallic salt; ${ }^{4}$ the reaction of a metallic oxide with the corresponding aqueous solution of a salt of the desired metal; ${ }^{3-5}$ the slow precipitation of HS with sodium hydroxide from a metal salt solution; ${ }^{4,8,11}$ the co-precipitation procedure employed for LDH synthesis, introduced by Newman and Jones. ${ }^{4}$ Additionally, the reaction of a metal oxide $(\mathrm{MeO})$ with zinc acetate in an aqueous media, was reported by Morioka et al. ${ }^{2}$ Some of these procedures demand strict control of experimental variables, especially $\mathrm{pH}$, temperature and concentration of the reactants to avoid the formation of sub-products like $\mathrm{Cu}(\mathrm{OH})_{2}$ and $\mathrm{CuO} .^{8}$

The chemical composition and physical characteristics like surface area, pore size, particle size, and structure of the final product are dependent on the reactants concentration, temperature, pressure and reaction time. ${ }^{3,4,8,22}$ Frequently, 
the product of synthesis must be submitted to subsequent steps of aging and cleansing, in order to eliminate most of the impurities that could alter the morphology and properties, and consequently the final use of the material.

As noted, the classical dispersion method employed by Meyn et al. ${ }^{3}$ and Bruschini and Hudson, ${ }^{5}$ using two compounds of the same metal, generates an HS material with a high degree of purity and crystallinity, but has the disadvantage of needing above $24 \mathrm{~h}$ of reaction time. Newman and Jones, ${ }^{4}$ Henrist et al. ${ }^{8}$ and Pereira et al. ${ }^{22}$ reacted copper nitrate with sodium hydroxide using precipitation, dispersion, and co-precipitation methods, respectively, in order to produce a copper HS material. They obtained good results using an elaborated method, by employing the salt at boiling temperature, vacuum conditions and long aging periods, in order to improve the degree of crystallinity of the material. Rajamathi and Kamath, ${ }^{23}$ reported the synthesis of HS using the hydrolysis of urea for long periods of times (1.25 to $7.5 \mathrm{~h}$ ). The complexity of all these procedures explains the difficulty in reproducing the synthesis of HS materials, which implies carefully monitoring and controlling all conditions at each of the steps in a routine way to obtain good quality materials.

All the previously mentioned works validates the importance of a simple procedure for the preparation of copper hydroxynitrate, like the one reported here based on the reaction of magnesium hydroxide with copper nitrate as described in equation 1 . High purity materials were obtained with minimal workout, short reaction times, and under normal environmental conditions.

$$
\begin{gathered}
4\left(\mathrm{Cu}\left(\mathrm{NO}_{3}\right)_{2}\right)_{(\mathrm{aq})}+3\left(\mathrm{Mg}(\mathrm{OH})_{2}\right) \rightarrow \\
2\left(\mathrm{Cu}_{2}(\mathrm{OH})_{3}\left(\mathrm{NO}_{3}\right)\right)_{(\mathrm{s})}+3\left(\mathrm{Mg}\left(\mathrm{NO}_{3}\right)_{2}\right)_{(\mathrm{aq})}
\end{gathered}
$$

The atomic absorption technique was used to evaluate the content of $\mathrm{Mg}$ and $\mathrm{Cu}$, both, in the hydroxy salt and in the wash waters of recently prepared materials. The possible presence of small amounts of magnesium was revealed by this technique. In fact, the copper content in the solid samples was more than 400 times larger than the magnesium content $(\mathrm{Cu} / \mathrm{Mg}$ molar ratio $=413)$. $\mathrm{A}$ contrasting situation was found for the supernatant solution in equilibrium with the solid material. In this case, the $\mathrm{Cu} / \mathrm{Mg}$ molar ratio was determined to be 1.35 , confirming the presence of a significant excess of copper nitrate.

The crystal structure of the copper(II) hydroxynitrate was determined by X-ray diffraction, as shown in Figure 2, where its diffraction pattern is compared with that of copper nitrate and magnesium hydroxide (Figure $2 \mathrm{a}-2 \mathrm{~b}$ ), respectively. The expanded view in the $2 \theta$ range of 20 to $70^{\circ}$ is shown in Figure 2d.

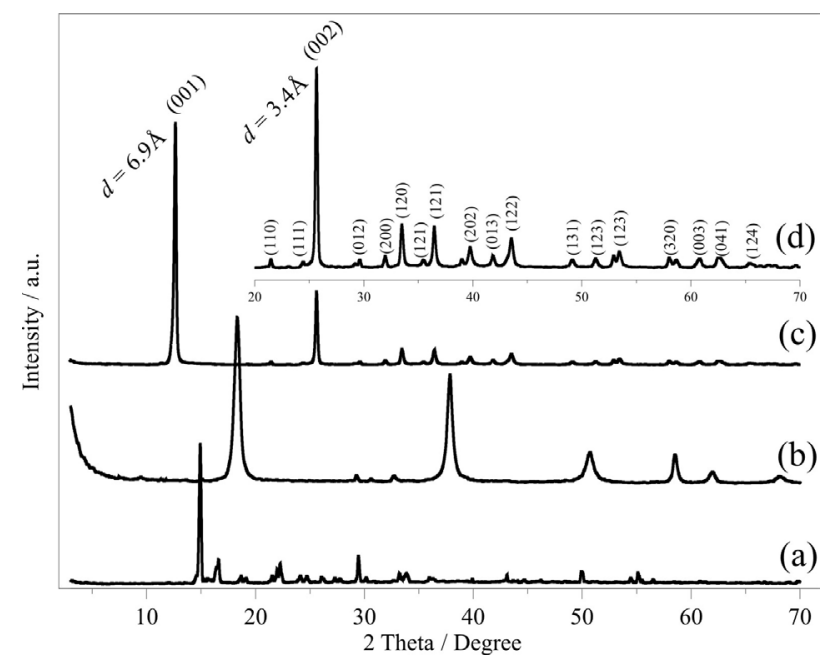

Figure 2. X-ray diffraction (XRD) patterns of (a) copper nitrate; (b) magnesium hydroxide; (c) full range and (d) zoomed (20-70 range) copper hydroxynitrate.

The high degree of crystallinity is evidenced by the presence of a series of sharp and well-defined $(00 l)$ reflections at periodic intervals, indicating the presence of a layered structure. The crystallographic phase was identified as belonging to the monoclinic P2 spatial group using the JCPDS-ICDD 75-1779 file, with cell parameters $\mathrm{a}=5.605 \AA, \mathrm{b}=6.087 \AA$, and $\mathrm{c}=6.929 \AA$, and $\beta=94.480^{\circ}$, at $25^{\circ} \mathrm{C}$. The $\mathrm{X}$-ray diffraction pattern, the Miller indexes for the main crystallographic planes, and the interlayer distances $\left(d_{(001)}=6.9 \AA\right.$ and $d_{(002)}=3.4 \AA$ ) for the copper hydroxynitrate are presented in Figure 2. The sharp reflections are in agreement with those reported in previous works. $3,4,17,24$

Clearly, a material with a crystalline phase distinct from that of copper nitrate and magnesium hydroxide precursors, with no peaks corresponding to $\mathrm{CuO}$ and/or $\mathrm{Cu}(\mathrm{OH})_{2}$, were obtained. In fact, all evidences are consistent with copper hydroxynitrate, with the formula $\mathrm{Cu}_{2}(\mathrm{OH})_{3} \mathrm{NO}_{3}$.

The FT-IR spectra of the magnesium hydroxide precursor and the prepared hydroxy salt are shown in Figure 3. Considering the structure of cooper hydroxynitrate some characteristic vibrational modes are expected in the IR spectrum. In the specific case of the metal-oxygen bond, strong peaks are expected between 150 and $450 \mathrm{~cm}^{-1}$. Medium intensity vibrational modes associated to the $\mathrm{Cu}-\mathrm{O}-\mathrm{H}$ bond should appear in the interval from 845 to $900 \mathrm{~cm}^{-1} \cdot{ }^{27}$ Strong peaks associated with the $\mathrm{NO}_{3}{ }^{-}$ion vibrational modes are also expected between 1340 and $1380 \mathrm{~cm}^{-1}$. Finally, the presence of water should lead to the appearance of a very strong peak around $1640 \mathrm{~cm}^{-1}$.

The IR spectrum of the magnesium hydroxide precursor is shown in Figure 3c. The strong bands centered at $3696 \mathrm{~cm}^{-1}$ and $3440 \mathrm{~cm}^{-1}$ were assigned to the stretching 


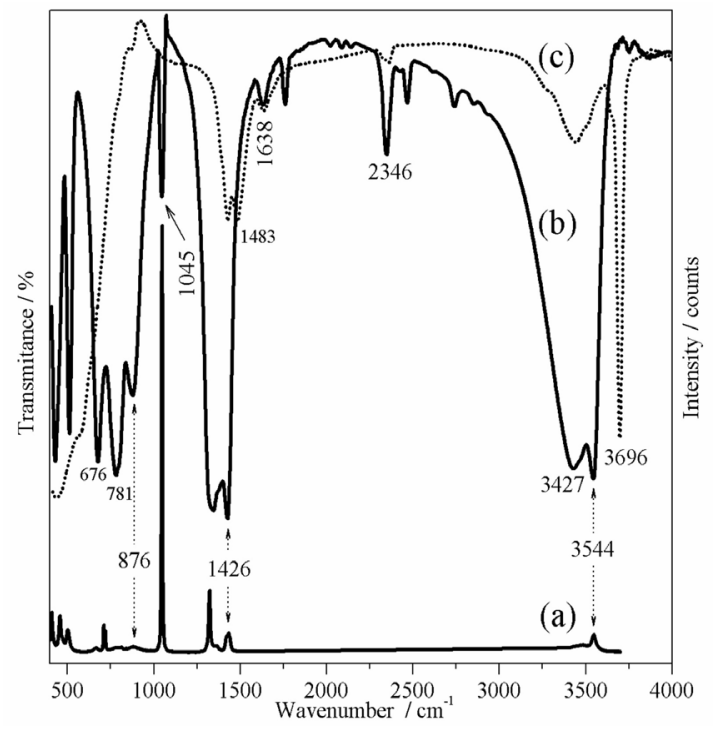

Figure 3. Raman (a) and FT-IR (b) spectrum of copper hydroxynitrate and (c) FT-IR of magnesium hydroxide.

modes of $\mathrm{OH}^{-}$groups, present in the layered structure and in the water molecules present in the interlamellar space. ${ }^{11}$ The peaks observed in the low frequency region were attributed to vibrational modes involving the $\mathrm{Mg}-\mathrm{OH}$ bonds. ${ }^{6}$

The peaks located at 1426 and $1483 \mathrm{~cm}^{-1}$ are consistent with those found by Frost and Kloprogge,${ }^{6}$ which show the presence of magnesite $\left(\mathrm{MgCO}_{3}\right)$, an impurity produced most likely through contamination with $\mathrm{CO}_{2}$ from the environment.

The IR spectrum of copper hydroxynitrate prepared according to the method reported here (Figure $3 b$ ) exhibited few vibrational peaks. The very sharp peak at $3544 \mathrm{~cm}^{-1}$ and the broad one at $3427 \mathrm{~cm}^{-1}$ can be assigned to structural $\mathrm{OH}^{-}$groups and to water molecules in the interlamellar space, respectively. Notice that a similar sharp peak was found in $\mathrm{Mg}(\mathrm{OH})_{2}$ but shifted to higher wavenumbers. $\left(3696 \mathrm{~cm}^{-1}\right.$ ) reflecting the influence of the $\mathrm{M}^{2+}-\mathrm{OH}$ bond. The bandwidth is related to the degree of hydrogen bonding among neighboring $\mathrm{OH}$ groups.

There are two peaks in this region. The narrow band at $3544 \mathrm{~cm}^{-1}$ corresponds to free $\mathrm{OH}$ groups, while the one centered at $3427 \mathrm{~cm}^{-1}$ indicates the presence of hydrogen bonded $\mathrm{OH}$ groups. ${ }^{11,22}$ The peaks at $1045\left(v_{1}\right), 800\left(v_{2}\right)$, 1343,1375 and $1426 \mathrm{~cm}^{-1}\left(v_{3}\right)$ can be assigned to vibrational modes of nitrate $\left(\mathrm{NO}_{3}^{-}\right)$ions, ${ }^{25}$ whose interaction with cooper hydroxide layers is evidenced by the appearance of symmetric and asymmetric stretching modes of $\mathrm{NO}_{3}{ }^{-}$at 1426 and $1343 \mathrm{~cm}^{-1}$. The band at $1045 \mathrm{~cm}^{-1}$ corresponds to the $\mathrm{N}-\mathrm{O}$ stretching vibration of a monodentate $\mathrm{O}-\mathrm{NO}$ group, which is active in both, FT-IR and Raman spectra (see Figure 4), in good agreement with the literature. ${ }^{22,26}$ The shoulder observed at $1375 \mathrm{~cm}^{-1}$ is also assigned to free nitrate ions in the interlamellar space.
The frequency of the vibrational modes attributed to $\mathrm{Cu}-\mathrm{O}-\mathrm{H}$ bonds are depend on the degree of hydrogen bonding and were found at 876,781 and $676 \mathrm{~cm}^{-1}$, in good agreement with those reported by Henrist et al. ${ }^{22}$ (876, 784, and $673 \mathrm{~cm}^{-1}$ ).

The synthesized copper hydroxynitrate exhibited some other vibrational peaks that were active in both infrared and Raman spectra (Figure 3c). The peak at $430 \mathrm{~cm}^{-1}$ was assigned to a $v(\mathrm{Cu}-\mathrm{O})$ vibrational mode, while the peak at $876 \mathrm{~cm}^{-1}$ was assigned to $\mathrm{Cu}-\mathrm{O}-\mathrm{H}$ vibrations. ${ }^{22}$ Another peak at $1426 \mathrm{~cm}^{-1}$ was attributed to vibrational modes of the nitrate group. A third peak at $1638 \mathrm{~cm}^{-1}$ has been assigned to a bending mode of the hydroxyl group of water. ${ }^{6}$

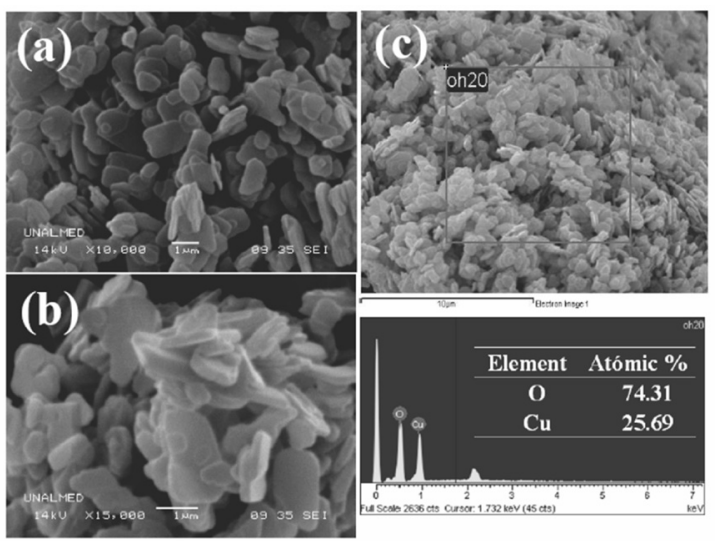

Figure 4. Scanning electron microscopy (SEM) images of copper hydroxynitrate at magnifications of (a) 10.000x and (b) 15.000x; and respective (c) energy-dispersive X-ray spectrum (SEM/EDX).

Several studies have been conducted on the morphology of layered double hydroxides and other types of clays; however there are few reports on hydroxy salts. ${ }^{28}$ The SEM images of copper hydroxynitrate are shown in Figure 4. The SEM images of the material show well crystallized particles with plate-like morphology (Figure 4) and average size of 1-2 $\mu \mathrm{m}$.

Only copper was found in the hydroxy salt by EDX analyses (Figure 4c) confirming a highly efficient substitution of magnesium ions by copper ions in the synthesis. The oxygen/copper molar ratio was found to be 2.9 by EDX, very close to the theoretical value of 3.0. This result is quite satisfactory keeping in mind the limitations of the technique.

The thermogravimetric analysis (TGA) curves and the differential thermogravimetric (DTG) curve for the copper hydroxynitrate in nitrogen atmosphere are illustrated in Figure 5. There are two events leading to a total weight loss of $38 \%$. The first one in the interval from $20^{\circ} \mathrm{C}$ to $150^{\circ} \mathrm{C}$, corresponding to a $15 \%$ weight loss, was attributed to the removal of weakly bond water molecules. The 


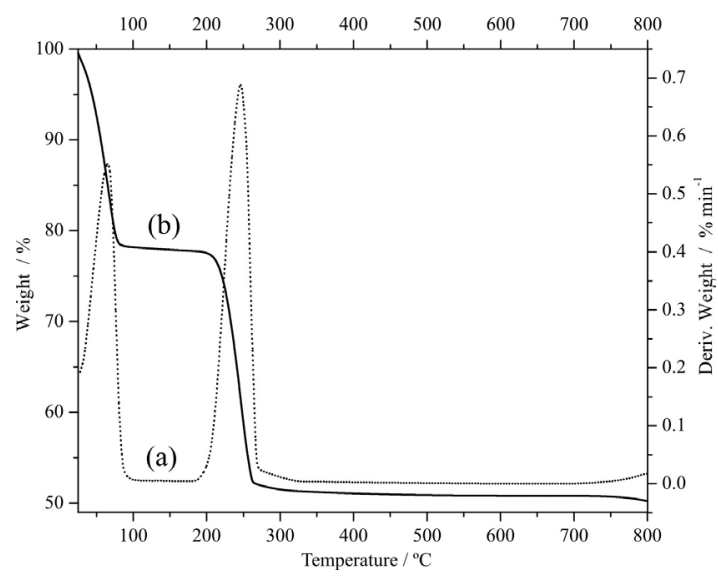

Figure 5. Thermogravimetric analysis curves, (a) DTG and (b) TGA, of copper hydroxynitrate.

second event with weight loss of $23 \%$, occurring in the $150{ }^{\circ} \mathrm{C}$ to $400{ }^{\circ} \mathrm{C}$ interval, can be assigned to the thermal decomposition and destruction of the layered structure through dehydroxylation reactions and transformation of nitrate ions (present in the interlayer space) to nitrogen oxides, as reported in the literature for hydroxy salt materials. ${ }^{5,29-31}$ The most commonly accepted mechanism for the thermal decomposition of copper hydroxynitrate is described by equation 2, which does not include the decomposition of nitric acid. ${ }^{22}$

$$
\mathrm{Cu}_{2}(\mathrm{OH})_{3}\left(\mathrm{NO}_{3}\right) \rightarrow 2(\mathrm{CuO})_{(\mathrm{s})}+\mathrm{HNO}_{3(\mathrm{~g})}+\mathrm{H}_{2} \mathrm{O}_{(\mathrm{g})}
$$

The thermal behavior of the material is shown in Figure 5. The first step (until up to $150^{\circ} \mathrm{C}$ ) was assigned to the loss of water molecules adsorbed in the surface and in the interlayer space. De-hydroxylation and decomposition of the anion in the interlayer space should take place in the second step, leading to the destruction of the layered structure. The temperature of the second thermal decomposition process (Figure 5) was found to be $246^{\circ} \mathrm{C}$ which is lower than for magnesium hydroxide $\left(377^{\circ} \mathrm{C}\right)$, evidencing its lower thermal stability.

\section{Conclusions}

A new and simple preparation method of copper hydroxynitrate $\left(\mathrm{Cu}_{2}(\mathrm{OH})_{3} \mathrm{NO}_{3}\right)$ by the reaction of magnesium hydroxide and copper nitrate aqueous solution was described. The method is fast and does not require any variation of temperature or pressure, being carried out in mild conditions. The product showed a high degree of crystallinity despite of the fact that the material was not subject to long aging periods, as reported in other works. Our method can be extended to the preparation of other analogous layered hydroxide materials based on transition metal ions such as nickel and cobalt. Studies in this direction are on the way in our laboratory.

\section{Acknowledgments}

The authors thank the Direction of Research (DIME) at National University of Colombia, Medellin Campus, for the economic support for this project (QUIPU code: 20101007735), and the Chemistry, Advanced Microscopy, Magnetism and Advanced Materials and Optics laboratories at this university for the analyses of Atomic Absorption, SEM/EDX, Raman, and TGA-DTG, respectively, and the laboratory of Analytic Chemistry at Quindío University for FT-IR analysis. Finally the authors thank Susan Diane Galvis for the helpful discussions of the manuscript.

\section{References}

1. Bera, P.; Rajamathi, M.; Hegde, M. S.; Kamath, P. V.; Bull. Mater. Sci. 2000, 23, 141.

2. Morioka, H.; Tagaka, H.; Karasu, M.; Kadokawa, J.; Chiba, K.; Inorg. Chem. 1999, 38, 4211.

3. Meyn, M.; Beneke, K.; Lagaly, G.; Inorg. Chem. 1993, 32, 1209.

4. Newman, S. P.; Jones, W.; J. Solid State Chem. 1999, 148, 26.

5. Bruschini, C. S.; Hudson, M. J.; Access in Nanoporous Materials; Pinnavaia, T. J.; Thorpe, M. F., eds.; Plenum Press: New York, 1995, p. 161.

6. Frost, R. L.; Kloprogge, J. T.; Spectrochim. Acta, Part A 1999, 55, 2195.

7. Rajamathi, M.; Thomas, G.; Kamath P.; Proc. Indian Acad. Sci. (Chem. Sci.) 2001, 113, 671.

8. Pereira, D. C.; de Faria, D. L. A.; Constantino, V. R. L.; J. Braz. Chem. Soc. 2006, 17, 1651.

9. Hawthorne, F. C.; Schindler, M.; Can. Mineral. 2000, 38, 751.

10. Frost, R. L.; Erickson, K. L.; Weier, M. L.; Leverett, P.; Williams, P. A.; Spectrochim. Acta, Part A 2005, 61, 607.

11. Rajamathi, J. T.; Britto, S.; Rajamathi, M.; J. Chem. Sci. 2005, 117, 629.

12. Fujita, W.; Awaga, K.; J. Am. Chem. Soc. 1997, 119, 4563.

13. Abdelouhab, S.; François, M.; Elkaim, E.; Rabu, P.; Solid State Sci. 2005, 7, 227.

14. Fujita, W.; Awaga, K.; Yokoyama, T.; Appl. Clay Sci. 1999, 15, 281.

15. Taibi, M.; Ammar, S.; Jouini, N.; Fiévet, F.; Molinié, P.; Drillon, M.; J. Mater. Chem. 2002, 12, 3238.

16. Kurmoo, M.; Kumagai, H.; Hughes, S. M.; Kepert, C. J.; Inorg. Chem. 2003, 42, 6709.

17. Park, S. H.; Lee, C. E.; J. Phys. Chem. B 2005, 109, 1118.

18. Arizaga, G. G. C. A.; Satyanarayana, K. G.; Wypych, F.; Solid State Ionics 2007, 178, 1143. 
19. Rabu, P.; Angelov, S.; Legoll, P.; Belaiche, M.; Drillon, M.; Inorg. Chem. 1993, 32, 2463.

20. Fujita, W.; Awaga, K.; Inorg. Chem. 1996, 35, 1915.

21. Laget, V.; Hornick, C.; Rabu, P.; Drillon, M.; Ziessel, R.; Coord. Chem. Rev. 1998, 178, 1533.

22. Henrist, C.; Traina, K.; Hubert, C.; Toussaint, G.; Rulmont, A.; Cloots, R.; J. Cryst. Growth 2003, 254, 176.

23. Rajamathi, M.; Kamath, P. V.; Int. J. Inorg. Mater. 2001, 3, 901.

24. Biswick, T.; Jones, W.; Pacula, A.; Serwicka, E.; J. Solid State Chem. 2006, 179, 49.

25. Nakamoto, K.; Infrared and Raman Spectra of Inorganic and Coordination Compounds, $4^{\text {th }}$ ed., John Wiley \& Sons: New York, 1986.
26. Arizaga, G. G. C.; Mangrich, A. S.; Ferreira, J. E.; Wypych, F.; J. Colloid Interface Sci. 2008, 320, 168.

27. Secco, E.; Worth, G.; Can. J. Chem. 1987, 65, 2504.

28. Morioka, H.; Tagaya, H.; Kadokawa, J. I.; Chiba, K.; J. Mater. Sci. Lett. 1999, 18, 995.

29. Kandare, E.; Hossenlopp, J. M.; Inorg. Chem. 2006, 45, 3766.

30. Rojas, R.; Barriga, C.; Ulibarri, M. A.; Malet, P.; Rives, V.; J. Mater. Chem. 2002, 12, 1071.

31. Rojas, R.; Ulibarri, M. A.; Barriga, C.; Rives, V.; Microporous Mesoporous Mater. 2008, 112, 262.

Submitted: December 3, 2009 Published online: November 12, 2010 